\title{
EFFECT OF COMBINING LOSARTAN AND PERINDOPRIL IN DIABETIC PATIENTS WITH PROTEINURIA
}

\author{
SHIN-CHEE CHIN, ADYANI MD REDZUAN* \\ Quality Use of Medicine Research Group, Faculty of Pharmacy, Universiti Kebangsaan Malaysia, Jalan Raja Muda Abdul Aziz, 50300 Kuala \\ Lumpur, Malaysia. Email: adyani@ukm.edu.my
}

Received: 27 May 2017, Revised and Accepted: 04 July 2017

\section{ABSTRACT}

Objective: This retrospective study compared the efficacy and safety of losartan monotherapy versus losartan and perindopril combination therapy in diabetic patients with hypertension and albuminuria. Factors affecting the change in albuminuria were identified.

Methods: Through quota sampling, the study recruited patients from a tertiary care hospital. Outcome parameters included urinary albumin creatinine ratio (UACR), blood pressure (BP), serum creatinine, and estimated glomerular filtration rate (eGFR). Both pre- and post-treatment measurements were traced from patient's medical records.

Results: No significant differences $(\mathrm{p}=0.615)$ were detected in the pre- and post-treatment change in UACR between the monotherapy group (-38.3 mg/g, interquartile range [IQR]:-618.8-0) and combination therapy group (-88.4 mg/g, IQR: - 729.3-+375.7). There was a considerably higher percentage of patients attaining the target BP of $<125 / 75 \mathrm{mmHg}$ in the combination group $(66.7 \%$; $<<0.001)$. In terms of safety, combined losartan and perindopril caused more hypotension ( $\mathrm{p}=0.003)$, higher rise in serum creatinine $(\mathrm{p}=0.481)$, and greater drop in eGFR $(\mathrm{p}=0.861)$. Body mass index was shown to have significant negative correlation with UACR reduction $(r=-0.449 ; \mathrm{p}=0.036)$.

Conclusion: The main finding of this study was that losartan alone was as equally efficacious as combined losartan and perindopril in lowering UACR and BP among diabetic patients.

Keywords: Albuminuria, Losartan, Perindopril, Hypertension, Urinary albumin creatinine ratio.

(C) 2017 The Authors. Published by Innovare Academic Sciences Pvt Ltd. This is an open access article under the CC BY license (http://creativecommons. org/licenses/by/4. 0/) DOI: http://dx.doi.org/10.22159/ajpcr.2017.v10i10.20253

\section{INTRODUCTION}

The renin-angiotensin system (RAS) is overactivated when concurrent medical illnesses such as hypertension and diabetes mellitus are present. Although the use of angiotensin-converting enzyme inhibitors (ACEIs) is effective, RAS blockade remains incomplete owing to a counter regulatory response caused by reactive hyperreninemia [1]. This, together with the activation of other tissue enzymes such as chymase, leads to the regeneration of plasma angiotensin II [2]. Therefore, an additional agent targeting the RAS is required particularly in preventing disease progression and further complications. In diabetes, a combination therapy of ACEI and angiotensin receptor blocker (ARB) are deemed effective in reducing albuminuria and delaying renal failure.

A number of studies have investigated on the efficacy and safety of combining ACEI and ARB in the management of diabetic population with micro- or macro-albuminuria, as defined by urinary albumin creatinine ratio (UACR) of 30-300 mg/g or $>300 \mathrm{mg} / \mathrm{g}$, respectively [3]. Two metaanalyses of small controlled trials revealed that dual RAS blockade resulted in additional reduction of UACR and systolic blood pressure (SBP) [4,5]. On the contrary, other studies did not show extra advantages but more harm by adding a second RAS blocker [6,7]. With these conflicting results, the latest kidney disease outcomes quality initiative guideline does not yet recommend dual ACEI and ARB treatment [8]. Further ongoing large-scaled trials are still underway $[9,10]$.

The prescribing of combined ACEI and ARB therapy remains widespread currently and is a practice without firm evidence support. This study is carried out to evaluate the effect of combining losartan and perindopril on UACR, BP, serum creatinine, and estimated glomerular filtration rate (eGFR) among a subgroup of diabetic patients with hypertension and albuminuria.

\section{METHODS}

This retrospective study was approved by the Research Ethic Committee of Universiti Kebangsaan Malaysia (UKM1.5.3.5/244/NF006-2013). Patients taking losartan from January 2012 to January 2013 were retrieved from the pharmacy system. A total of 769 patients were identified. Screening was done to select patients who were diabetics. They were categorized into monotherapy group (losartan alone) and combination group (losartan plus perindopril). Patients' medical case files were traced from the record unit. At least two UACR readings must be available; pre-treatment UACR was the UACR reading within 3 weeks before treatment initiation whereas post-treatment UACR was the UACR reading after at least 1 month of treatment. Similarly, pre- and post-treatment BP, serum creatinine, eGFR, and serum potassium were recorded. eGFR was calculated using the Cockcroft-Gault formula. The use of concurrent antihypertensives from other pharmacological classes was allowed, and the regimens were stabilized before the initiation of study drugs. Those who were diagnosed with end-stage renal failure and defaulted first follow-up were excluded. Based on these inclusion and exclusion criteria, a total number of 22 patients were recruited as suitable participants (10 receiving losartan alone; 12 receiving concurrent losartan and perindopril).

The change in UACR, defined as the difference between pre-and post treatment UACR reading, was evaluated regardless of dosage regimen, together with the change in BP, serum creatinine, eGFR and serum potassium. Parametric statistical tests were employed for normally distributed continuous data while non-parametric tests for nominal or ordinal data and continuous data with skewed distribution. Correlation analysis was also carried out to investigate determinant factors of UACR reduction. Results were presented in percentage, mean with standard deviation, or median with interquartile range (IQR). 


\section{RESULTS}

The baseline characteristics of patients are presented in Table 1. All patients were comparable in terms of age, gender, body mass index (BMI), smoking status, alcoholic status, and history of ischemic heart disease (IHD). The majority of the patients were Type II diabetics, with only a quarter $(n=3)$ in the combination group was diagnosed as Type I diabetics. Macroalbuminuria was significantly more common in the combination group as compared to the monotherapy group $(p<0.001)$. The pre-treatment readings of outcome parameters among the study groups did not show significant differences, except for UACR reading (monotherapy $627.64 \pm 794.8 \mathrm{mg} / \mathrm{g}$ vs. combination $1856.4 \pm 2285.1 \mathrm{mg} / \mathrm{g} ; \mathrm{p}=0.012$ ).

In terms of the change in UACR between pre- and post-treatment, there were no significant differences $(\mathrm{p}=0.571)$ found between the monotherapy group $(-38.3 \mathrm{mg} / \mathrm{g}$, IQR: 618.8$)$ and combination group $(-88.4 \mathrm{mg} / \mathrm{g}$, IQR: 1105). The result is presented in Table 2. Despite the lack of significant differences in BP reduction between the study groups (change in SBP, $\mathrm{p}=0.617$; change in diastolic $\mathrm{BP}, \mathrm{p}=0.695$ ), there was a higher percentage of participants in the combination group achieving target $\mathrm{BP}$ of $<125 / 75 \mathrm{mmHg}(\mathrm{p}<0.001)$. The result is presented in Table 3. The changes in serum creatinine $(p=0.481)$ and eGFR $(p=0.861)$ were not significantly affected by the type of therapy; whether it was losartan alone or losartan plus perindopril. However, the combination regimen had caused a higher rise in serum creatinine $(6.08 \pm 18 \mu \mathrm{mol} / \mathrm{L}$ vs. $-0.8 \pm 16.2$ $\mu \mathrm{mol} / \mathrm{L})$ along with a further drop in kidney function $(-1.51 \pm 15.4 \mathrm{ml} /$ minute $/ 1.73 \mathrm{~m}^{2 \text { vs. }}-0.56 \pm 7.7 \mathrm{ml} /$ minute $/ 1.73 \mathrm{~m}^{2}$ ).

\section{DISCUSSION}

Losartan therapy or combined losartan and perindopril therapy were similarly effective in lowering proteinuria and BP. This was supported by results from ONTARGET trial [6], although CALM study [11] and a few meta-analyses $[4,5]$ suggested the opposite. Although the mean reduction of UACR in the combination group was slightly but not significantly higher than the group on single therapy, this favorable outcome might be offset by the increment in mean serum creatinine along with a reduction in mean eGFR as seen in the current study. The same findings were observed in the ONTARGET and TRANSCEND studies [12]. In other words, for optimal control of proteinuria, we may need to spare the risk of causing more damage on the kidney and hence the loss of renoprotective functions of ACEI and ARB.

Both dual and single therapy were good in controlling BP although the former was not significantly more effective than the latter. The total antihypertensive responses were minor, but this should not be neglected in the current study because as little as $2-3 \mathrm{mmHg}$ drop in SBP could contribute to a cardiovascular risk reduction of 4-5\% [13]. A greater proportion of patients managed to achieve target BP with the use of combined losartan and perindopril. Nonetheless, more patients in the combination group had developed hypotension $(p=0.003)$. This could be explained by the synergistic action of losartan and perindopril on RAS, resulting in further drops in BP.

In the current study, a significant negative correlation was found between the patient's BMI and UACR reduction ( $\mathrm{r}=-0.449$; $\mathrm{p}=0.036)$.

Table 1: Baseline characteristics of the study population according to therapy group

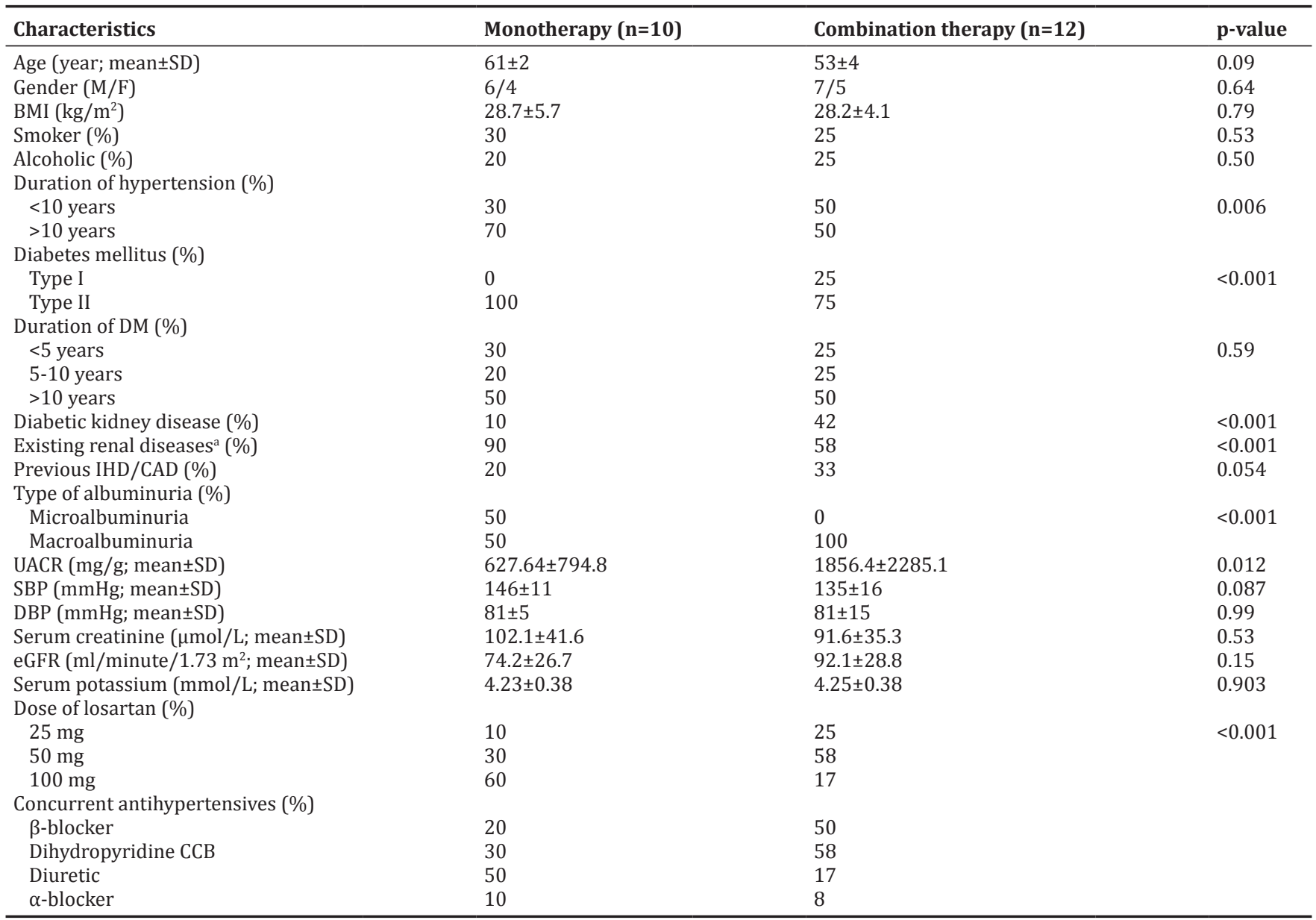

aExisting renal diseases: Not attributable to diabetes. SD: Standard deviation, DM: Diabetes mellitus, BMI: Body mass index, CAD: Coronary artery disease, IHD: Ischemic heart disease, UACR: Urinary albumin creatinine ratio, SBP: Systolic blood pressure, DBP: Diastolic blood pressure, eGFR: Estimated glomerular filtration rate, CCB: Calcium-channel blockers 
Table 2: Change in UACR between losartan and losartan plus perindopril

\begin{tabular}{lllll}
\hline Variable & \multicolumn{2}{l}{ Median (IQR) } & Z statistic & p value \\
\cline { 2 - 4 } & $\begin{array}{l}\text { Losartan } \\
\text { alone }(\mathbf{n}=\mathbf{1 0})\end{array}$ & $\begin{array}{l}\text { Losartan plus } \\
\text { perindopril (n=12) }\end{array}$ & -0.503 & 0.615 \\
\hline $\begin{array}{l}\text { Change } \\
\text { in UACR } \\
(\mathrm{mg} / \mathrm{g})\end{array}$ & $-38.3(618.8)$ & $-88.4(1105)$ & \\
\hline IQR: Interquartile range, UACR: Urinary albumin creatinine ratio & &
\end{tabular}

Table 3: Change in SBP and DBP between losartan and losartan plus perindopril

\begin{tabular}{lllc}
\hline Variable & Mean \pm SD & p value \\
\cline { 2 - 3 } & Losartan alone (n=10) & Losartan plus perindopril (n=12) & 0.617 \\
\hline Change in SBP (mmHg) & $-10.8 \pm 16.7$ & $-7.4 \pm 14.5$ & 0.695 \\
Change in DBP (mmHg) & $-3.5 \pm 10.8$ & $-5.8 \pm 16.2$ & $<0.001$ \\
Percentage of participants achieving target $\mathrm{BP}<125 / 75 \mathrm{mmHg}(\%)$ & 20 & 66.7 & \\
\hline
\end{tabular}

SBP: Systolic blood pressure, DBP: Diastolic blood pressure, BP: Blood pressure

This result coincided with that discovered by Rossi et al. in the DEMAND study [14]. Other patient factors such as gender, age, and history of IHD were poorly related with UACR reduction; as opposed with what had been established previously $[3,15,16]$.

This study has highlighted the potential advantages and drawbacks of cotherapy using losartan and perindopril in treating diabetic patients with albuminuria. Nevertheless, the findings should be deduced with caution owing to several limitations such as limited sample size, sampling bias, and the existence of confounding variables (e.g. nonstandardized patient's review date, changes in diet, medication compliance, and physical activities). Therefore, the results may not be generalizable to the entire population.

\section{CONCLUSION}

Our study findings did not support the concurrent use of losartan and perindopril for the treatment of albuminuria in hypertensive diabetics population. Until the results of ongoing trials and further safety data emerge, it is recommended to withhold its use in general practice, especially for low kidney-risk patients and maybe for those with advanced kidney disease. If used, patients' renal function should be monitored closely, as there is no sufficient evidence of safety.

\section{REFERENCES}

1. Mooser V, Nussberger J, Juillerat L, Burnier M, Waeber B, Bidiville J, et al. Reactive hyperreninemia is a major determinant of plasma angiotensin II during ACE inhibition. J Cardiovasc Pharmacol 1990;15(2):276-82.

2. Rakugi H, Wang DS, Dzau VJ, Pratt RE. Potential importance of tissue angiotensin-converting enzyme inhibition in preventing neointima formation. Circulation 1994;90(1):449-55.

3. National Kidney Foundation. KDOQI clinical practice guideline for chronic kidney disease: Evaluation, classification and stratification. Am J Kidney Dis 2002;39 2 Suppl 1:S1-266.

4. Pham JT, Schmitt BP, Leehey DJ. Effects of dual blockade of the reninangiotensin system in diabetic kidney disease: A systematic review and meta-analysis. J Nephrol Ther 2012;S2:003.

5. Kunz R, Friedrich C, Wolbers M, Mann JF. Meta-analysis: Effect of monotherapy and combination therapy with inhibitors of the renin angiotensin system on proteinuria in renal disease. Ann Intern Med 2008;148(1):30-48.

6. ONTARGET Investigators, Yusuf S, Teo KK, Pogue J, Dyal L, Copland I, et al. Telmisartan, ramipril, or both in patients at high risk for vascular events. N Engl J Med 2008;358(15):1547-9.

7. Pfeffer MA, McMurray JJ, Velasquez EJ, Rouleau JL, Køber L, Maggioni AP, et al. For the valsartan in acute myocardial infarction trial investigators. Valsartan, captopril or both in myocardial infarction complicated by heart failure, left ventricular dysfunction, or both. N Engl J Med 2003;349(20):1839-1906.

8. National Kidney Foundation. KDOQI Clinical Practice Guideline for Diabetes and CKD: 2012 update. Am J Kidney Dis 2012;60(5):850-6.

9. Clinical Trials at Villa Camozzi. Preventing ESRD in Overt Nephropathy of Type 2 Diabetes. The VALID Trial. 2012. Available from: http://www.clintrials.marionegri.it/index.php/main-trials/maintrials-ongoing/70.html. [Last accessed on $2013 \mathrm{Feb} 25]$.

10. Fried LF, Duckworth W, Zhang JH, O'Connor T, Brophy M, Emanuele $\mathrm{N}$, et al. Design of combination angiotensin receptor blocker and angiotensin-converting enzyme inhibitor for treatment of diabetic nephropath y (VA NEPHRON-D). Clin J Am Soc Nephrol 2009;4(2):361-8

11. Mogensen CE, Neldam S, Tikkanen I, Oren S, Viskoper R, Watts RW, et al. Randomised controlled trial of dual blockade of reninangiotensin system in patients with hypertension, micro albuminuria, and noninsulin dependent diabetes: The Candesartan and Lisinopril Microalbuminuria (CALM) study. BMJ 2000;321(7274):1440-4.

12. Tobe SW, Clase CM, Gao P, McQueen M, Grosshennig A, Wang X, et al. Cardiovascular and renal outcomes with telmisartan, ramipril, or both in people at high renal risk: Results from the ONTARGET and TRANSCEND studies. Circulation 2011;123(10):1098-7.

13. Vasan RS, Larson MG, Leip EP, Evans JC, O'Donnell CJ, Kannel WB, et al. Impact of high-normal blood pressure on the risk of cardiovascular disease. N Engl J Med 2001;345(18):1291-7.

14. Rossi MC, Nicolucci A, Pellegrini F, Comaschi M, Ceriello A, Cucinotta $\mathrm{D}$, et al. Obesity and changes in urine albumin/creatinine ratio in patients with Type 2 diabetes: The DEMAND study. Nutr Metab Cardiovasc Dis 2010;20(20):110-6.

15. Bildirici U, Ural E, Kilic T, Aygun F, AcarE, Cekmen M, et al. Association between documented coronary artery disease and urinary albumin, albumin to creatinine ratio. Med Sci Monit 2010;16(11):CR545-8.

16. Epstein M. Aging and the kidney. J Am Soc Nephrol 1996;7(8):1106-22. 